\title{
Bone mineral accretion rate and calcium intake in preterm infants
}

\author{
A HORSMAN, S W RYAN, ${ }^{*}$ P J CONGDON, ${ }^{*} \mathrm{~J}$ G TRUSCOTT, AND M SIMPSON \\ MRC Bone Mineralisation Group, Department of Medical Physics, and ${ }^{*}$ Regional Neonatal Surgical and \\ Intensive Care Unit, The General Infirmary, Leeds
}

SUMmARY Thirty six preterm infants ( 20 boys) of 25 to 32 weeks' gestation were observed from birth to around 40 weeks' postconception. When oral feeding became possible, nine received mother's own breast milk (group B), 15 formula feed (group F), and 12 formula feed supplemented with calcium $(5 \mathrm{ml} 10 \%$ calcium gluconate $/ 100 \mathrm{ml}$ feed) and phosphorus $(0.5 \mathrm{ml}$ $17 \%$ potassium phosphate similarly) (group S). All received a daily supplement of 400 IU vitamin D. Intakes of calcium, phosphorus, vitamin D, energy, and fluid volume were recorded. When oral feeding started, and near 40 weeks' postconception, bone mineral content of the forearm was measured by photon absorptiometry; weight and crown-heel length were also measured.

After logarithmic transformation of the measurements, there were no significant intergroup differences between the mean rate constants for weight or crown-heel length describing growth during the observation period. The mean rate constant for mineral accretion (M) was significantly higher in group $S$ than in both the others. Pooling all data, $M$ was significantly correlated with calcium intake but not with any other variable. Mineral supplementation of feed can reduce but not cure osteopenia of prematurity.

By applying single photon absorptiometry to the mid forearm of neonates, ${ }^{1}$ we have previously shown the existence of a substantial deficit in bone mineral content, relative to full term infants observed at birth, in most preterm infants when they reach a postconceptional age of 40 weeks. ${ }^{2} 3$

Bone mineral content of cortical bone is dependent on both density of mineralisation and bone size in the measurement region. Infants with extremely low birth weight (ELBW) (that is, birth weight less than $1000 \mathrm{~g}$ ) have recently been shown to be at a disadvantage in both respects. ${ }^{3}$ At about 40 weeks they are underweight by $45 \%$, shorter by $20 \%$, and undermineralised by $55 \%$ relative to full term controls observed at birth; taking into account their reduced body size, at 40 weeks ELBW infants are still undermineralised by $35 \%$. Preterm infants with birth weights in excess of $1000 \mathrm{~g}$ have also been shown to be undermineralised at $\mathbf{4 0}$ weeks by about $20 \%$ when body size reduction is taken into account. ${ }^{2}$ Numerical values of relative undermineralisation observed in such studies, based as they were on localised measurements of the peripheral skeleton, do not necessarily apply to the skeleton as a whole; none the less, a mineral deficit in the forearm bones of a preterm infant is usually indicative of more widespread osteopenia.

Radiographically detectable osteopenia of prematurity has reportedly been ameliorated by vitamin D supplementation. ${ }^{4}$ However, radiological assessment detects only the most severe cases. In contrast, our measurements of the effects of vitamin D supplementation of randomly selected preterm infants did not show a significant improvement in the rate of postnatal mineral accretion when the vitamin D intake was raised from the standard 400 IU/day to 1000 IU/day (J James, PJ Congdon, A Horsman, et al. Unpublished observations). In the same study, infants given $1 \alpha$-hydroxyvitamin $D$ had a slightly raised rate of mineral accretion but still did not reach values comparable with those attained in utero. ${ }^{5}$

There is, however, some evidence that bone mineral accretion can be accelerated by mineral supplementation, ${ }^{6}$ and given the lack of response to vitamin D supplements we consequently gave calcium and phosphorus supplemented feeds to some of the preterm infants in our neonatal unit. In this 
paper we present observations of changes in bone mineral content in preterm infants some of whom were given breast milk, the remainder being offered either normal feeds or feeds supplemented with calcium and phosphorus, the aim being to determine whether mother's milk or increased mineral intake conferred detectable benefits with respect to mineral accretion rate and general growth parameters.

\section{Patients and methods}

This study was authorised by the local ethical committee and commenced in September 1986, being carried out over a period of 17 months. During that period, all white infants of less than 33 weeks' gestation who were born in The General Infirmary, Leeds, or transferred to our neonatal unit during the first week of life, were considered eligible for the study. Those who were transferred back to their referring hospitals before the initial assessment could be performed were excluded.

Parents of 36 infants consented to the recruitment of their child into the study, having been approached soon after the birth. Gestational age (completed weeks) and birth weight were noted in each case. Gestational age, calculated from maternal menstrual history and confirmed by either external examination ${ }^{7}$ or ophthalmoscopic examination of the lens ${ }^{8}$ ranged from 25 to 32 weeks and birth weight from 650 to $2000 \mathrm{~g}$. Descriptive statistics for observations at birth are contained in table 1 for each of the three dietary groups described below.

Most infants received intravenous fluids immediately after birth and, if fluids were required for three days or more, total parenteral nutrition was then implemented using standard solutions supplying up to $60 \mathrm{mg} / \mathrm{kg} /$ day calcium, $40 \mathrm{mg} / \mathrm{kg} /$ day phosphorus, and $200 \mathrm{IU} /$ day vitamin $\mathrm{D}$. When the infants were able to tolerate oral feeds they were allocated to one of three dietary groups: breast milk, formula fed, and supplemented groups denoted by $\mathrm{B}, \mathrm{F}$, and $\mathrm{S}$, respectively.
Mothers who wished to feed their infants with breast milk were allowed to do so. The infants in this group, B, received expressed milk until able to feed at the breast. Nine infants (seven boys) out of the 36 participants in this study were fed in that way throughout the individual period of observation. Each received an oral daily supplement of 400 IU vitamin $\mathrm{D}$.

Those infants whose mothers did not wish to breast feed were given standard cows' milk formula feeds, including the standard daily supplement of 400 IU vitamin D, with or without additional mineral supplementation. The unsupplemented feed contained calcium and phosphorus in concentrations in the ranges 44 to 61 and 27 to $50 \mathrm{mg} / 100 \mathrm{ml}$ respectively and was received by 15 infants (six boys) comprising group $\mathrm{F}$. The additional supplement was allocated on a random basis and consisted of $5 \mathrm{ml} 10 \%$ calcium gluconate plus $0.5 \mathrm{ml} 17 \cdot 4 \%$ dipotassium hydrogen phosphate added to each 100 $\mathrm{ml}$ bottle of ready made feed. Concentrations of calcium and phosphorus in the supplemented feed, which was received by 12 infants (seven boys) comprising group $\mathrm{S}$, were in the ranges 86 to 102 and 46 to $62 \mathrm{mg} / 100 \mathrm{ml}$ of prepared feed respectively; dilution caused a reduction in energy content of about $5 \%$.

Infants in group $S$ were screened for hypercalcaemia or hyperphosphataemia on a weekly basis. No deleterious effects of this form of supplementation were observed. When the supplemented infants were discharged from the neonatal unit, mineral supplements were discontinued in view of the potential errors and dangers involved in adding mineral supplements at home. The infants then received standard cows' milk formula feed.

For each infant, calcium, phosphorus, vitamin D, energy, and fluid intakes were assessed for every day in the period between the two absorptiometric scans (see below). Calcium and phosphorus concentrations in breast milk were taken to be 25 and 17 $\mathrm{mg} / 100 \mathrm{ml}$ respectively, based on analyses of pooled samples from eight mothers. Most of the informa-

Table 1 Descriptive statistics for gestational age and weight at birth in the breast milk group (B), the formula fed group $(F)$, and the group of infants given calcium and phosphorus supplemented feeds (S)

\begin{tabular}{|c|c|c|c|c|c|c|}
\hline & \multicolumn{2}{|l|}{ Group $B(n=9)$} & \multicolumn{2}{|l|}{ Group $F(n=15)$} & \multicolumn{2}{|l|}{ Group $S(n=12)$} \\
\hline & $\begin{array}{l}\text { Gestational age } \\
\text { (weeks) }\end{array}$ & $\begin{array}{l}\text { Birth weight } \\
(g)\end{array}$ & $\begin{array}{l}\text { Gestational age } \\
\text { (weeks) }\end{array}$ & $\begin{array}{l}\text { Birth weight } \\
\text { (g) }\end{array}$ & $\begin{array}{l}\text { Gestational age } \\
\text { (weeks) }\end{array}$ & $\begin{array}{l}\text { Birth weight } \\
(g)\end{array}$ \\
\hline Mean & $28 \cdot 22$ & 1219 & $29 \cdot 67$ & 1254 & $30 \cdot 17$ & 1426 \\
\hline SD & 1.64 & 288 & $2 \cdot 16$ & 316 & 1.85 & 296 \\
\hline Minimum & 25 & 925 & 26 & 950 & 27 & 650 \\
\hline Maximum & 30 & 1750 & 32 & 2000 & 32 & 1800 \\
\hline
\end{tabular}


tion about intakes was obtained from dietary records; however, for each infant discharged from the neonatal unit before the second scan, the dietary intakes after discharge were estimated from a diet history taken when the second scan was performed. Mean values of calcium and phosphorus intakes in $\mathrm{mg} / \mathrm{kg} /$ day, vitamin D intake in IU/day, energy intake in $\mathrm{MJ} / \mathrm{kg} /$ day (except in group B) and fluid intake in $\mathrm{ml} / \mathrm{kg} /$ day were evaluated for each infant. Individual total calcium and phosphorus intakes were divided by individual observation periods to provide average rates of nutrient intake in g/week. Descriptive statistics for the dietary variables are given in table 2 .

In all infants within seven weeks of birth, and in most (29 out of 36) within three weeks of birth, bone mineral content was measured at the middle of the right forearm by photon absorptiometry as described in previous publications. ${ }^{12}$ The radiation exposure involved in this procedure is very small, and only a narrow area of the forearm is irradiated during a scan; skin entrance dose is $0.03 \mathrm{mGy}$ per

Table 2 Descriptive statistics for estimates of dietary intakes of calcium, phosphorus, vitamin D, energy, and fluids for the three dietary groups between the first and second absorptiometric scans

\begin{tabular}{|c|c|c|c|c|c|c|c|c|c|c|}
\hline & \multicolumn{3}{|l|}{ Calcium } & \multicolumn{3}{|l|}{ Phosphorus } & \multicolumn{2}{|c|}{ Vitamin $D$} & \multirow{2}{*}{$\begin{array}{l}\text { Energy } \\
(M J / k g / \text { day })\end{array}$} & \multirow{2}{*}{$\begin{array}{l}\text { Fluids } \\
(\mathrm{ml} / \mathrm{kg} / \text { day })\end{array}$} \\
\hline & $m g / k g / d a y$ & $g$ & g/week & $m g / k g / d a y$ & $g$ & g/week & IU/day & $I U$ & & \\
\hline \multicolumn{11}{|c|}{ Group B $(n=9)$ : } \\
\hline Mean & $52 \cdot 31$ & $7 \cdot 35$ & 0.713 & $36 \cdot 87$ & $5 \cdot 14$ & $0 \cdot 501$ & 400 & 27820 & - & $187 \cdot 6$ \\
\hline $\mathrm{SD}$ & $7 \cdot 62$ & 3.47 & $0 \cdot 264$ & $5 \cdot 91$ & $2 \cdot 42$ & $0 \cdot 192$ & - & 5656 & - & $20 \cdot 9$ \\
\hline Minimum & $39 \cdot 40$ & $2 \cdot 38$ & 0.415 & $29 \cdot 10$ & $1 \cdot 75$ & $0 \cdot 303$ & 400 & 15988 & - & $149 \cdot 4$ \\
\hline Maximum & $67 \cdot 30$ & $12 \cdot 98$ & $1 \cdot 218$ & $49 \cdot 90$ & $8 \cdot 80$ & 0.907 & 400 & 35196 & - & $216 \cdot 7$ \\
\hline \multicolumn{11}{|c|}{ Group $F(n=15)$ : } \\
\hline Mean & $92 \cdot 49$ & $7 \cdot 52$ & $1 \cdot 035$ & $63 \cdot 51$ & $5 \cdot 29$ & 0.721 & 483.9 & 25467 & 0.483 & $177 \cdot 6$ \\
\hline SD & $20 \cdot 32$ & $3 \cdot 25$ & $0 \cdot 361$ & $15 \cdot 71$ & $2 \cdot 73$ & $0 \cdot 313$ & $79 \cdot 7$ & 7630 & $0 \cdot 041$ & $15 \cdot 7$ \\
\hline Minimum & $51 \cdot 30$ & $2 \cdot 72$ & 0.464 & $41 \cdot 80$ & 1.59 & $0 \cdot 232$ & $311 \cdot 0$ & 12757 & $0 \cdot 400$ & $146 \cdot 6$ \\
\hline Maximum & $113 \cdot 30$ & $12 \cdot 40$ & 1.621 & $92 \cdot 20$ & $10 \cdot 17$ & $1 \cdot 329$ & $595 \cdot 0$ & 42115 & $0 \cdot 556$ & $202 \cdot 0$ \\
\hline \multicolumn{11}{|c|}{ Group $S(n=12)$} \\
\hline Mean & $136 \cdot 60$ & $12 \cdot 57$ & $1 \cdot 690$ & 81.99 & $7 \cdot 44$ & 0.994 & $518 \cdot 1$ & 26984 & $0 \cdot 482$ & $184 \cdot 3$ \\
\hline SD & $36 \cdot 83$ & $5 \cdot 10$ & $0 \cdot 374$ & $15 \cdot 56$ & $3 \cdot 38$ & 0.267 & $70 \cdot 7$ & 9717 & $0 \cdot 038$ & $11 \cdot 0$ \\
\hline Minimum & $95 \cdot 60$ & $6 \cdot 81$ & $1 \cdot 147$ & $64 \cdot 70$ & 3.95 & 0.675 & $359 \cdot 0$ & 14644 & $0 \cdot 396$ & $167 \cdot 7$ \\
\hline Maximum & $233 \cdot 30$ & $19 \cdot 86$ & $2 \cdot 255$ & $112 \cdot 70$ & $15 \cdot 45$ & 1.774 & $618 \cdot 0$ & 40916 & $0 \cdot 544$ & $204 \cdot 8$ \\
\hline
\end{tabular}

Table 3 Descriptive statistics for observations at the time of the first scan. Weight, crown-heel length, and bone mineral content were measured in the mid forearm at that time for the three dietary groups. Natural logarithms are denoted by $1 n$

\begin{tabular}{|c|c|c|c|c|c|c|c|}
\hline & \multirow{2}{*}{$\begin{array}{l}\text { Postconcep- } \\
\text { tional age } \\
\text { (weeks) }\end{array}$} & \multicolumn{2}{|c|}{ Weight } & \multicolumn{2}{|c|}{ Crown-heel length } & \multicolumn{2}{|c|}{ Bone mineral content } \\
\hline & & $g$ & $\ln$ & $\mathrm{cm}$ & $\ln$ & $\mathrm{mg} / \mathrm{cm}$ & $\ln$ \\
\hline \multicolumn{8}{|c|}{ Group B $(n=9)$ : } \\
\hline Mean & $30 \cdot 29$ & 1188 & $7 \cdot 062$ & $38 \cdot 87$ & $3 \cdot 658$ & $95 \cdot 56$ & $4 \cdot 540$ \\
\hline SD & 0.72 & 247 & 0.203 & $2 \cdot 60$ & 0.066 & $19 \cdot 90$ & $0 \cdot 213$ \\
\hline Minimum & $29 \cdot 00$ & 910 & $6 \cdot 813$ & $35 \cdot 20$ & $3 \cdot 561$ & $70 \cdot 81$ & $4 \cdot 260$ \\
\hline Maximum & $31 \cdot 29$ & 1600 & $7 \cdot 378$ & $43 \cdot 30$ & $3 \cdot 768$ & $126 \cdot 41$ & $4 \cdot 840$ \\
\hline \multicolumn{8}{|c|}{ Group F $(n=15)^{*}$ : } \\
\hline Mean & 31.92 & 1252 & $7 \cdot 105$ & $39 \cdot 28$ & 3.669 & $101 \cdot 06$ & 4.599 \\
\hline SD & 1.45 & 317 & $0 \cdot 236$ & $2 \cdot 35$ & 0.060 & $19 \cdot 26$ & $0 \cdot 192$ \\
\hline Minimum & $29 \cdot 29$ & 825 & $6 \cdot 715$ & $35 \cdot 30$ & $3 \cdot 564$ & 71.62 & $4 \cdot 271$ \\
\hline Maximum & $35 \cdot 00$ & 2000 & $7 \cdot 601$ & $43 \cdot 20$ & 3.766 & $140 \cdot 93$ & 4.948 \\
\hline \multicolumn{8}{|c|}{ Group $S(n=12)$ : } \\
\hline Mean & $31 \cdot 76$ & 1342 & $7 \cdot 190$ & 39.92 & 3.685 & $101 \cdot 03$ & $4 \cdot 604$ \\
\hline SD & 1.64 & 214 & $0 \cdot 161$ & $2 \cdot 12$ & 0.055 & $14 \cdot 73$ & $0 \cdot 160$ \\
\hline Minimum & $28 \cdot 29$ & 950 & $6 \cdot 856$ & $34 \cdot 60$ & $3 \cdot 544$ & $66 \cdot 55$ & $4 \cdot 198$ \\
\hline Maximum & $34 \cdot 00$ & 1700 & $7 \cdot 438$ & $43 \cdot 10$ & $3 \cdot 764$ & $121 \cdot 98$ & $4 \cdot 804$ \\
\hline
\end{tabular}

${ }^{*} \mathrm{n}=14$ for crown-heel length. 
investigation. Postconceptional ages at the time of the first scan ranged from 28 to 35 weeks. Weight (in g) and crown-heel length (in $\mathrm{cm}$ ) were measured at the same time. A crown-heel length measurement was not taken in one case. Descriptive statistics for observations performed at this time are contained in table 3.

Between the postconceptional ages of 37 and 43 weeks bone mineral content, weight, and crownheel length were measured again. Crown-heel length was not measured in one case; this was a different infant from the one in whom crown-heel length was not measured on the first scan. The interval between the first and second scans ranged from 3.7 to 12.6 weeks (mean 8.0 weeks). Descriptive statistics for observations performed at the time of the second scan are contained in table 4 .

\section{STATISTICAL ANALYSIS}

Individual values of weight, crown-heel length, and bone mineral content were converted to logarithms to the base $e$ because previously published intrauterine data indicated that logarithmic transformation is appropriate ${ }^{5}$; individual infants were assumed to follow exponential growth curves for all three variables during the postconceptional age range covered by these investigations. Individual rate constants (that is, rates of change of the natural logarithms of the measurements) were calculated by dividing the changes in the logarithms by the corresponding time intervals of observation (in weeks) between the first and second scans. Student's $t$ test was used to evaluate the significances of observed mean changes within and mean differences between groups; significances of differences in mean rate constants between groups were evaluated similarly. Paired $t$ tests were used in comparisons of the preterm infants with full term infants observed previously and matched for postconceptional age at the time of photon absorptiometry.

\section{Results}

With one exception, there were no significant intergroup differences in the mean values of gestational age and weight at birth (table 1). Infants in group B had a significantly lower mean gestational age (28.22 weeks) than those in group $S(30.17$ weeks; p<0.05).

The data in table 2 show the disadvantage of breast feeding and the effectiveness of supplementation with regard to mineral intakes. As percentages of the mean $\mathrm{mg} / \mathrm{kg} /$ day value in the group $\mathrm{F}$, calcium and phosphorus intakes were $57 \%$ and $58 \%$ respectively in group B and $148 \%$ and $129 \%$ respectively in group S. Intergroup differences in the mean values of intake expressed as $\mathrm{mg} / \mathrm{kg} /$ day were all highly significant $(p<0.01)$; with the exception of the difference in phosphorus intake between groups $B$ and $F$, differences between intakes expressed as

Table 4 Descriptive statistics for observations at the time of the second scan. Weight, crown-heel length, and bone mineral content were measured in the mid forearm at that time for the three dietary groups. Natural logarithms are denoted by ln

\begin{tabular}{|c|c|c|c|c|c|c|c|}
\hline & \multirow{2}{*}{$\begin{array}{l}\text { Postconcep- } \\
\text { tional age } \\
\text { (weeks) }\end{array}$} & \multicolumn{2}{|c|}{ Weight } & \multicolumn{2}{|c|}{ Crown-heel length } & \multicolumn{2}{|c|}{ Bone mineral content } \\
\hline & & $g$ & $\ln$ & $\mathrm{cm}$ & $\ln$ & $m g / c m$ & $\ln$ \\
\hline \multicolumn{8}{|c|}{ Group B $(n=9)$ : } \\
\hline Mean & $40 \cdot 22$ & 2685 & $7 \cdot 850$ & 46.99 & $3 \cdot 845$ & $96 \cdot 12$ & $4 \cdot 528$ \\
\hline SD & 1.67 & 811 & 0.332 & $4 \cdot 53$ & 0.097 & $29 \cdot 60$ & 0.284 \\
\hline Minimum & 37.00 & 1350 & $7 \cdot 208$ & $39 \cdot 70$ & $3 \cdot 681$ & $66 \cdot 38$ & $4 \cdot 195$ \\
\hline \multicolumn{8}{|c|}{ Group F $(n=15)^{*}$ : } \\
\hline Mean & $39 \cdot 18$ & 2399 & $7 \cdot 753$ & $46 \cdot 20$ & $3 \cdot 830$ & $98 \cdot 53$ & $4 \cdot 575$ \\
\hline SD & $1 \cdot 11$ & 580 & 0.256 & $3 \cdot 59$ & 0.079 & $16 \cdot 88$ & $0 \cdot 185$ \\
\hline Minimum & $37 \cdot 14$ & 1400 & $7 \cdot 244$ & $39 \cdot 10$ & 3.666 & 60.88 & $4 \cdot 109$ \\
\hline Maximum & $40 \cdot 86$ & 3400 & $8 \cdot 132$ & $51 \cdot 80$ & 3.947 & $126 \cdot 80$ & $4 \cdot 843$ \\
\hline Mean & $39 \cdot 13$ & 2453 & $7 \cdot 782$ & $46 \cdot 43$ & $3 \cdot 836$ & $116 \cdot 68$ & $4 \cdot 742$ \\
\hline SD & 1.66 & 562 & $0 \cdot 222$ & $2 \cdot 72$ & 0.059 & $20 \cdot 26$ & $0 \cdot 203$ \\
\hline Minimum & $37 \cdot 29$ & 1850 & $7 \cdot 523$ & $41 \cdot 00$ & $3 \cdot 714$ & 64.95 & $4 \cdot 174$ \\
\hline Maximum & $42 \cdot 71$ & 3600 & $8 \cdot 189$ & $51 \cdot 80$ & 3.947 & 148.49 & $5 \cdot 001$ \\
\hline
\end{tabular}

${ }^{*} n=14$ for crown-heel length. 
$\mathrm{g} /$ week were also significant $(\mathrm{p}<0.05)$. Mean calcium:phosphorus ratio (based on the $\mathrm{mg} / \mathrm{kg} /$ day figures) was higher in group $S(1.67)$ than in the other two groups (1.42 in group B and 1.46 in group F).

Values given in table 2 for vitamin $D$ intake do not include the component present in the mother's milk fed to group B. The mean intake (IU/day) in group $S$ was higher by about $7 \%$ than the mean in group F; this difference is mainly an indirect result of the fact that infants in group $S$ tended initially to be slightly heavier and therefore were offered more feed than those in group $F$ (see the mean weight values in tables 3 and 4). Mean energy intake $(\mathrm{MJ} / \mathrm{kg} /$ day), however, did not differ between groups $\mathrm{F}$ and $\mathrm{S}$ (table 2; data were not available for group B), nor were there significant differences between the three groups with respect to fluid intake.

It was anticipated from the way the study was performed that there would be no systematic differences between the groups at the time of the first scan. Results at this time are given in table 3. Although the postconceptional age was significantly lower in group $B$ than in group $F(p<0.01)$ and group $S(p<0.05)$, the differences between the means were small (less than 1.7 weeks). There were no significant intergroup differences between the mean values of weight, crown-heel length, and bone mineral content, or between the mean values of the logarithms of those measurements at the time of the first scan.

Results at the time of the second scan are given in table 4. Mean values of postconceptional age at that time did not differ significantly between groups and occupied the range 39.13 to 40.22 weeks. Group B was the heaviest (mean $2685 \mathrm{~g}$ ) but there were no significant weight (or ln weight) differences between groups. Group B was also the longest (mean crownheel length $46.99 \mathrm{~cm}$ ) but again there were no significant intergroup differences. Similar mean values of bone mineral content were attained at this time by groups $B$ and $F$, although the variance was greater in the former. Both mean bone mineral content and its logarithmic equivalent, however, were significantly higher in group $S$ than in group $F$ $(p<0.02$ and $p<0.05$ for bone mineral content and its natural logarithm respectively). The figure summarises the results obtained at the times of the first and second scans.

Mean values of the time interval between birth and the first scan were $2 \cdot 1,2 \cdot 3$, and $1 \cdot 6 \cdot$ weeks for groups $\mathrm{B}, \mathrm{F}$, and $\mathrm{S}$, respectively and were not significantly different from one another. For the three groups together, the mean was 2.0 weeks with individual time intervals ranging from 1 day to $7 \cdot 0$ weeks. The interval was less than three weeks in $78 \%$ of cases and less than two weeks in $58 \%$. During that period, some infants gained while others lost weight. The rate of weight change for all infants averaged (SEM) -25 (17) g/week and was not significantly different from zero. Individual changes in weight ranged from $-280 \mathrm{~g}$ to $+300 \mathrm{~g}$. Such changes are consistent with common clinical experience of preterm infants.

Absolute changes in the mean values of the measurements can be derived from tables 3 and 4 . The mean (SD) interval between the first and
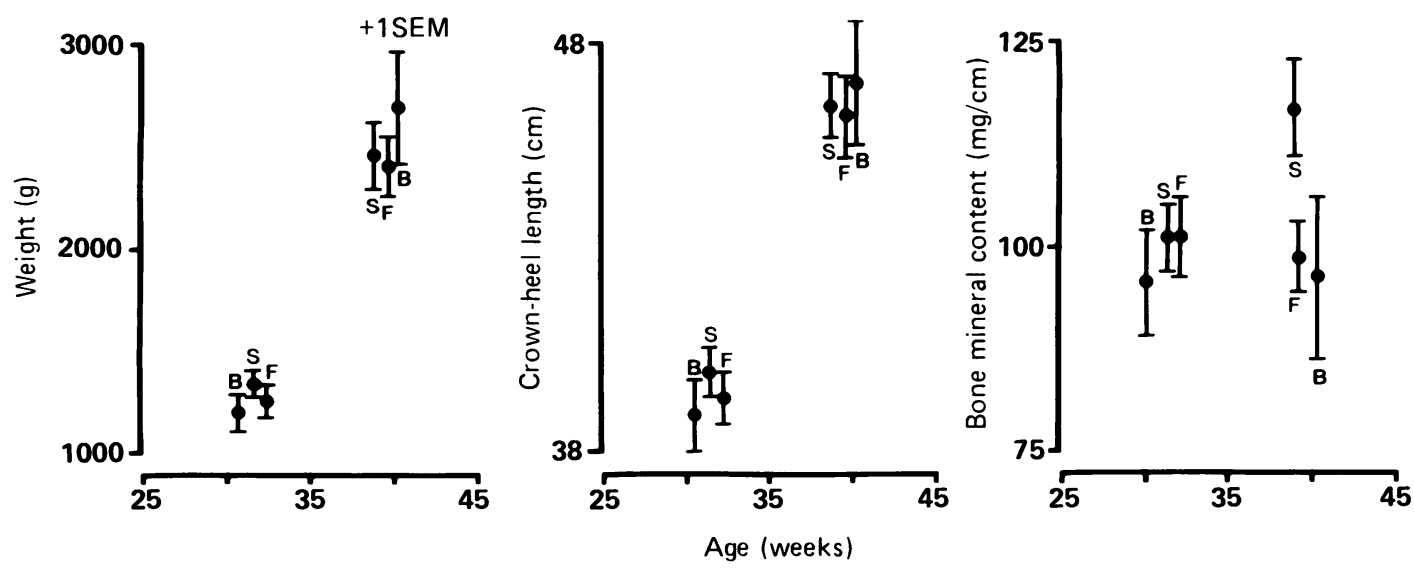

Figure Mean (SEM) of weight, crown-heel length, and bone mineral content of the mid forearm in the three dietary groups at the times of the first and second absorptiometric scans. $B=$ brcast milk, $F=$ formula, and $S=$ supplement. 
Bone mineral accretion rate and calcium intake in preterm infants 915

second scans varied between groups however, it was $9.94(2.02)$ weeks in group B, $7.26(1.87)$ weeks in group $\mathrm{F}$, and $7.37(2.20)$ weeks in group $\mathrm{S}$. Significant differences between the mean interval in group $B$ and both the other groups $(p<0.02)$ make interpretation of absolute changes difficult. Instead, rates of change of the measurements were compared.
Results derived from individual rates of change of the measurements and individual rate constants are given in tables 5 and 6 respectively. Values in table 5 are the weekly changes in the raw measurements and were evaluated only as a guide to the growth rates. Statistical tests were not performed on those results as it is known that the rate of change of each of the three variables is itself an increasing function

Table 5 Rates of change (weekly changes in measurements) for weight, crown-heel length, and bone mineral content of the mid forearm in the three dietary groups. Results apply to the period between the first and second scans

\begin{tabular}{|c|c|c|c|}
\hline & \multicolumn{3}{|l|}{ Rates of change } \\
\hline & Weight (g/week) & $\begin{array}{l}\text { Crown-heel length } \\
\text { (cm/week) }\end{array}$ & $\begin{array}{l}\text { Bone mineral content } \\
(\mathrm{mg} / \mathrm{cm} / \text { week })\end{array}$ \\
\hline \multicolumn{4}{|c|}{ Group B $(n=9)$ : } \\
\hline Mean & $144 \cdot 6$ & 0.790 & -0.027 \\
\hline SD & 45.9 & 0.251 & 2.027 \\
\hline Minimum & $61 \cdot 3$ & 0.385 & $-3 \cdot 126$ \\
\hline Maximum & $222 \cdot 5$ & 1.055 & $+2 \cdot 541$ \\
\hline \multicolumn{4}{|c|}{ Group F $(n=15)^{*}$ : } \\
\hline Mean & 153.9 & 0.998 & -0.560 \\
\hline SD & $47 \cdot 0$ & 0.409 & 1.782 \\
\hline Minimum & $75 \cdot 0$ & $0 \cdot 550$ & $-3 \cdot 234$ \\
\hline Maximum & $238 \cdot 1$ & $2 \cdot 289$ & $+2 \cdot 510$ \\
\hline \multicolumn{4}{|c|}{ Group $S(n=12)$ : } \\
\hline Mean & 148.5 & 0.905 & $2 \cdot 349$ \\
\hline SD & $37 \cdot 6$ & $0 \cdot 206$ & 2.013 \\
\hline Minimum & $80 \cdot 7$ & 0.631 & $-1 \cdot 118$ \\
\hline Maximum & $211 \cdot 1$ & $1 \cdot 356$ & $+5 \cdot 235$ \\
\hline
\end{tabular}

${ }^{*} \mathrm{n}=13$ for crown-heel length.

Table 6 Rate constants (weekly changes in natural logarithms of measurements) for weight, crown-heel length, and bone mineral content of the mid forearm in the three dietary groups. Results apply to the period between the first and second scans and were used for evaluation of the significance of intergroup differences of the means

\begin{tabular}{|c|c|c|c|}
\hline & \multicolumn{3}{|c|}{ Rate constants } \\
\hline & Weight & Crown-heel length & Bone mineral content \\
\hline \multicolumn{4}{|c|}{ Group B $(n=9)$ : } \\
\hline Mean & 0.0781 & $0 \cdot 01836$ & -0.0018 \\
\hline SD & 0.0132 & 0.00536 & 0.0207 \\
\hline SEM & $0 \cdot 0044$ & 0.00179 & 0.0069 \\
\hline \multicolumn{4}{|c|}{ Group F $(n=15)^{*}$ : } \\
\hline Mean & 0.0881 & 0.02319 & -0.0057 \\
\hline SD & 0.0229 & 0.00848 & 0.0202 \\
\hline SEM & 0.0059 & 0.00235 & 0.0052 \\
\hline \multicolumn{4}{|c|}{ Group $S(n=12)$ : } \\
\hline Mean & 0.0811 & 0.02112 & 0.0207 \\
\hline SD & 0.0177 & 0.00523 & 0.0175 \\
\hline SEM & 0.0051 & $0 \cdot 00151$ & 0.0051 \\
\hline
\end{tabular}

*n=13 for crown-heel length. 
of postconceptional age; the growth curves are exponential. Mean rate of weight gain was about the same in all three groups (about $150 \mathrm{~g} /$ week); within all three groups there was a wide spread in the individual rate of weight gain, with maximum values approximately three times the minimum values. Group B appeared to grow in length least rapidly (see below), mean values of the rate of increase of crown-heel length being similar in the other two groups (about $1 \mathrm{~cm} /$ week); again there was wide variability between individuals, with maximum values of the rate of crown-heel length increase being two to four times the minimum values. Based on the rate constants in table 6 there were no significant intergroup differences in weight increase or linear growth. For bone mineral content, however, the mean rate constant was significantly higher in group $S$ than in both the other two groups ( $p<0.01$ for groups $S$ and $F$, and $p<0.02$ for groups $\mathrm{S}$ and $\mathrm{B})$. There was no evidence within any group that the distribution of any rate constant was other than normal.

Correlations between rate constants for weight, crown-heel length and bone mineral content were evaluated. Within the groups, there were only two significant correlations, both involving weight and crown-heel length: in group $B, r=0.80(p<0.02)$ and in group $F, r=0.62(p<0.05)$. Pooling results in the three groups, again only the correlation coefficient between the rate constants for crown-heel length and weight was significant $(r=0.60 ; p<0.0002)$. The rate constant for bone mineral content was not significantly correlated with the rate constant for either crown-heel length or weight.

For calcium and phosphorus, individual intakes expressed both as $\mathrm{mg} / \mathrm{kg} /$ day and $\mathrm{g} /$ week (averaged over the period between the two scans) were available. In the case of calcium, pooling the results in the three groups, the rate constant for bone mineral content was significantly correlated with the intake expressed as $\mathrm{mg} / \mathrm{kg} /$ day $(\mathrm{r}=0.43 ; \mathrm{p}<0.01)$ and as $\mathrm{g} /$ week $(\mathrm{r}=0.36 ; \mathrm{p}<0.05)$. In the case of phosphorus, the corresponding associations were not significant $(r=0.22$ and $r=0.09$ respectively).

None of the rate constants for weight, crown-heel length, or bone mineral content (again pooling the results in the three groups) was significantly correlated with energy intake $(\mathrm{MJ} / \mathrm{kg} /$ day $)$ or fluid intake $(\mathrm{ml} / \mathrm{kg} /$ day $)$. The correlation coefficient between the rate constant for bone mineral content and vitamin $\mathrm{D}$ intake (IU/day) was $0.30(0.05<\mathrm{p}<0.1)$; the vitamin $\mathrm{D}$ intake was not correlated with any other variable at the significance level $p<0 \cdot 1$. All possible correlations within each group were also evaluated. There were no associations significant at the level $\mathrm{p}<0 \cdot 05$.
It was possible to match, on the basis of postconceptional age at the time of observation, nine of the infants in group $S$ with nine full term white infants observed in previous studies. ${ }^{2}$ The matching tolerance was less than one week; seven of the nine pairs were also sex matched. The matching exercise was limited to group $S$ because the expected difference between preterm and full term infants in the mean value of bone mineral content was least in that group. Paired $t$ tests were used to examine the significance of differences in the group mean values of weight, crown-heel length, and bone mineral content between the preterm and full term infants. Mean postconceptional age was almost identical in the two groups (39.7 weeks). The preterm infants were significantly lighter (preterm mean $2579 \mathrm{~g}$; full term mean $3470 \mathrm{~g} ; \mathrm{p}<0.01$ ) and shorter (preterm crown-heel length mean $46.8 \mathrm{~cm}$; full term mean $51.0 \mathrm{~cm} ; \mathrm{p}<0.01)$. Despite the fact that supplementation promotes bone mineral accretion, the mean value of bone mineral content in the preterm infants was significantly less than in the matched full term controls (preterm bone mineral content mean $113.9 \mathrm{mg} / \mathrm{cm}$; full term value $211.0 \mathrm{mg} / \mathrm{cm}$; $\mathrm{p}<0.001)$.

\section{Discussion}

Osteopenia of prematurity results from postnatal failure to match the rate of skeletal mineral accretion achieved in utero. ${ }^{56}$ It is likely that reduced accretion is at least partly a consequence of relative lack of mineral (calcium and phosphorus) in the diet. Supportive evidence for this view is provided by the observation that the mineral supply is particularly deficient in human milk (see table 2), a feed which has previously been shown to be associated with poor calcium retention and an increased risk of osteopenia. ${ }^{9-11}$ Furthermore, despite the insensitivity of radiological assessment of skeletal mineralisation, ${ }^{12}$ studies based on radiographic examination have shown a very high prevalence of rickets in extremely low birthweight infants fed human milk. ${ }^{13}$ Higher activities of alkaline phosphatase in blood, indicative of metabolic bone disease, have also been recorded in premature infants fed human milk. ${ }^{14}$

A reasonable approach to the treatment or prevention of osteopenia, therefore, is to increase dietary mineral intake. When offering a supplemented diet to a preterm infant, however, it has to be accepted that the skeletal response is likely to depend on both the size of the supplement and the formulation of the feed, with variations in mineral bioavailability causing variations in mineral absorption between different formulations. ${ }^{15}$ Whatever the 
response is, it can be measured, albeit with considerable technical difficulty, by calcium balance studies because a large proportion of total body calcium is located in the skeleton. Using that approach, Day et al showed that addition of calcium lactate to infant milk feeds resulted in calcium retention equal to that attained in utero ${ }^{16}$; however, in their study ionic hypercalcaemia occurred in over half the treated patients and the disparity between calcium retention $(160 \mathrm{mg} / \mathrm{kg} / \mathrm{day})$ and phosphorus retention (25 $\mathrm{mg} / \mathrm{kg} /$ day) remains unexplained. A similar disparity is present in the results of a study performed by Moya and Domenech that was probably too short (three days) to provide a reliable estimate of longer term calcium retention. ${ }^{17}$ More recent studies, in which specially prepared feeds were used that are not routinely available, have shown that mineral supplementation of formula feeds may result in calcium retention comparable with that achieved in utero. $^{18} 19$ Further evidence of the benefits of mineral supplementation has been provided by radiographic studies which showed fewer abnormal wrist radiographs in infants receiving mineral supplemented formula feed. ${ }^{20}$

From a technical standpoint, it is preferable to measure changes in skeletal mineralisation using photon absorptiometry, rather than calcium balance or radiological techniques, because the method provides a precise and accurate direct measurement of the bone mineral content at the scan site. ${ }^{12}$ Absorptiometric data on the effect of human milk feeding on changes in bone mineral content are confusing. A significant fall in bone mineral content during human milk feeding has been shown, ${ }^{21} 22$ but a significant fall has been shown in formula fed infants too. ${ }^{22}$ The addition of mineral supplements to human milk feeds has been found to confer no extra advantage in promoting bone mineral accretion. $^{23}$

The first workers to report normalised rates of bone mineralisation, based on absorptiometric data, in preterm infants given supplemented feeds were Steichen and Tsang. ${ }^{6}$ Unlike the infants in our study, theirs received not only mineral but also vitamin D supplements; furthermore the groups were not accurately described and the control group unexpectedly had a significantly lower mean value of bone mineral content at 2 weeks of age than the supplemented group despite the fact that both received the same feed for the first six days of life. However, there is evidence that the very smallest infants do not do so well. A further study by the same group, in which the benefits of mineral and vitamin $D$ supplementation in infants weighing less than $1500 \mathrm{~g}$ were investigated, showed that in two thirds of the infants bone mineral content increased, while in one third of the cases bone mineral content fell. ${ }^{24}$ Chan et al studied mineral supplementation in carefully selected infants who weighed less than $1600 \mathrm{~g}$; they excluded from their study infants who were ventilated, those who received more than $50 \%$ ambient oxygen, those with sepsis or intraventricular haemorrhage and those who received total parenteral nutrition for more than five days. ${ }^{21}$ Thus infants most at risk of osteopenia due to nutritional compromise were excluded. None the less, in that study also, some infants appeared to respond to supplementation by increasing bone mineral content whereas others suffered a net loss of bone mineral. A more recent study using very high concentrations of mineral in formula feed $(180 \mathrm{mg} / 100 \mathrm{ml}$ calcium and $90 \mathrm{mg} / 100 \mathrm{ml}$ phosphorus) showed a significant increase in bone mineral content, but the increase did not match the change expected in utero. ${ }^{22}$ The risk of mineral precipitation at such concentrations is quite high and supplementation to this level is well above present guidelines. ${ }^{25}$ At the much lower concentrations used in our study, we found no evidence of mineral precipitation.

The selection of infants at reduced risk of osteopenia, the use of complicated formula feeds, and the concomitant use of vitamin $D$ as well as mineral supplements, has made the interpretation of the results of previous studies and the choice of an optimal dietary regime in preterm infants difficult for the practising paediatrician. With this in mind, in our study we regarded all infants as eligible for study no matter how ill they were, we used a simple method of mineral supplementation using standard cows' milk formula, and we used no vitamin D supplement over and above the standard supplement of $400 \mathrm{IU} /$ day. Furthermore, no attempt was made to increase mineral accretion rates to the values achieved in utero because sick preterm infants often do not match intrauterine rates of growth in weight and length.

Under those conditions, we have shown that mineral supplementation of formula feeds confers a small but significant benefit in terms of mineral accretion rate, with rates of weight and length increase being independent of the dietary regimes studied. No side effects such as acidosis ${ }^{26}$ and necrotising enterocolitis ${ }^{27}$ occurred in the supplemented group. Although fat malabsorption has previously been shown in infants given mineral supplemented milk ${ }^{28}{ }^{29}$ there was no evidence of reduced weight gain in our supplemented infants. We therefore conclude that mineral supplementation of formula feed at the levels used in our study is a worthwhile and safe approach to the reduction of ostepenia of prematurity in all infants whose mothers choose not to breast feed. 


\section{Horsman, Ryan, Congdon, Truscott, and Simpson}

While this work was being carried out, S W Ryan was supported by a grant from the Special Trustees of The General Infirmary at Leeds while A Horsman, M Simpson, and J G Truscott were supported by the Medical Research Council.

\section{References}

1 James JR, Truscott J, Congdon PJ, Horsman A. Measurement of bone mineral content in the human fetus by photon absorptiometry. Early Hum Dev 1986;13:169-81.

2 James JR, Congdon PJ, Truscott J, Horsman A, Arthur R. Osteopenia of prematurity. Arch Dis Child 1986;61:871-6.

${ }^{3}$ Horsman A, Ryan SW, Congdon PJ, Truscott JG, James JR. Osteopenia in extremely low birthweight infants. Arch Dis Child 1989;64:485-8.

${ }^{4}$ Hillman LS, Hollis B, Salmons S, et al. Absorption, dosage and effect on mineral homeostasis of 25-hydroxycholecaliferol in premature infants. Comparison with 400 and $800 \mathrm{IU}$ vitamin $\mathrm{D}_{2}$ supplementation. J Pediatr 1985;106:981-9.

5 Ryan SW, Congdon PJ, James JR, Truscott J, Horsman A. Mineral accretion in the human fetus. Arch Dis Child 1988;63:799-808.

${ }^{6}$ Steichen JJ, Tsang RC. Osteopenia of prematurity; the cause and possible treatment. $J$ Pediatr 1980;96:249-52.

7 Parkin JM, Hey EN, Clowes JS. Rapid assessment of gestational age at birth. Arch Dis Child 1976;51:259-63.

${ }^{8}$ Hittner HM, Hirsch NJ, Rudolph AJ. Assessment of gestational age by examination of the anterior vascular capsule of the lens. $J$ Pediatr 1977;91:455-8.

9 Sagy M, Birenbaum E. Phosphate depletion syndrome in a premature infant fed human milk. J Pediatr 1980;96:683-5.

10 Lyon AJ, McIntosh N. Calcium and phosphorus balance in extremely low birthweight infants in the first six weeks of life. Arch Dis Child 1984;59:1145-50.

1 Schanler RJ, Garza C, O'Brian Smith E. Fortified mothers' milk for very low birth weight infants: results of macromineral balance studies. $J$ Pediatr 1985;107:767-74.

12 Lachman E. Osteoporosis: potentialities and limitations of its roentgenologic diagnosis. AJR 1955;74:712-8.

${ }^{13}$ Lyon AJ, McIntosh N, Wheeler K, Brooke OG. Hypercalcaemia in extremely low birthweight infants. Arch Dis Child 1984;59: 1141-4.

14 Rowe J, Rowe D, Horak E, et al. Hypophosphataemia and hypercalcuria in small premature infants fed human milk: evidence for inadequate dietary phosphorus. $J$ Pediatr 1984;104:112-7.

15 Schanler RJ, Abrams SA, Garza C. Bioavailability of calcium and phosphorus in human milk fortifiers and formula for very low birth weight infants. J Pediatr 1988;113:95-100.

16 Day GM, Chance GW, Radde IC, Reilly J, Park E, Sheepers J. Growth and mineral metabolism in very low birthweight infants.
II Effects of calcium supplementation on growth and divalent cations. Pediatr Res 1975;9:568-75.

17 Moya M, Domenech E. Role of calcium-phosphate ratio of milk formulae on calcium balance in low birth weight infants during the first three days of life. Pediatr Res 1982;16:675-81.

${ }^{18}$ Rowe JC, Goetz CA, Carty DE, Horak E. Achievement of in utero retention of calcium and phosphorus accompanied by high calcium excretion in very low birth weight infants fed a fortified formula. J Pediatr 1987;110:581-5.

19 Giles MM, Featon MH, Shaw B, et al. Sequential calcium and phosphorus balance studies in preterm infants. $J$ Pediatr 1987;110:591-8.

20 Laing IA, Glass EJ, Hendry GMA, et al. Rickets of prematurity: calcium and phosphorus supplementation. $J$ Pediatr 1985;106:265-8.

${ }^{21}$ Chan GM, Mileur L, Hansen JW. Effects of increased calcium and phosphorus formulas and human milk on bone mineralisation in preterm infants. J Pediatr Gastroenterol Nutr 1986;5:444 9.

22 Greer FR, McCormick A. Improved bone mineralization and growth in premature infants fed fortified own mother's milk. $J$ Pediatr 1988;112:961-9.

23 Gross SJ. Bone mineralization in preterm infants fed human milk with and without mineral supplementation. $J$ Pediatr 1987;111:450-8.

${ }^{24}$ Greer FR, Steichen J, Tsang RC. Effects of increased calcium, phosphorus and vitamin $\mathrm{D}$ intake on bone mineralization in very-low-birth-weight infants fed formulas with polycose and medium-chain triglycerides. J Pediatr 1982;100:951-5.

25 Bremer HJ, Brooke OG, Orzalesi M, et al. Nutrition and feeding of preterm infants. Acta Paediatr Scand 1987;336 (suppl): 2-14.

${ }^{26}$ Kildeberg P, Engel K, Winters RW. Balance of net acid in growing infants: Endogenous and transintestinal aspects. Acta Paediatr Scand 1969;58:321-9.

${ }^{27}$ Herbst JJ. Diet and necrotising enterocolitis. In: Moore TD, ed. Necrotising enterocolitis in the newborn infant. 68th Ross Conference on Pediatric Research. Columbus, Ohio: Ross Laboratories, 1975:71-4.

${ }^{28}$ Katz L, Hamilton JR. Fat absorption in infants of birthweight less than 1,300 gm. $J$ Pediatr 1974;85:608-14.

${ }^{29}$ Chappell JE, Clandinin MT, Kearney-Volpe C, Reichman B, Swyer PW. Fatty acid balance studies in premature infants fed human milk or formula: effect of calcium supplementation. $J$ Pediatr 1986;108:439-47.

Correspondence to Dr A Horsman, MRC Bone Mineralisation Group, Department of Medical Physics, Leeds General Infirmary, The Wellcome Wing, Great George Street, Leeds LS1 3EX.

Accepted 18 January 1989 